\title{
A Exceção como Prática: as Políticas de Pacificação no Rio de Janeiro (2008-2015)
}

Thiago Rodrigues;

Flávia Rodrigues de Castro;

Thaiane Mendonça

O campo como localização deslocante é a matriz oculta da política em que ainda vivemos, que devemos aprender a reconhecer através de todas as suas metamorfoses, nas zones d'attente de nossos aeroportos bem como em certas periferias de nossas cidades. Giorgio Agamben, "Homo Sacer. O poder soberano e a vida nua."

\section{Introdução}

No mundo clássico, bem representado através das obras de Platão e Aristóteles, os gregos não possuíam um termo único para exprimir o sentido da palavra "vida", mas o faziam através da utilização de dois termos distintos: zoé, a vida natural comum a todos os seres vivos, e bíos, a vida política, que indica a forma de viver específica de indivíduos ou grupos. A vida natural ou biológica é excluída, assim, no mundo clássico, do âmbito da pólis, permanecendo confinada ao oîkos, isto é, à esfera privada na qual tem lugar apenas as atividades de subsistência e de reprodução da vida. Já a vida política, por outro lado, deve seu pertencimento à ekklesia, que representa não o simples ato de viver e reproduzir, mas a vida politicamente qualificada (Agamben, 2014a). 
É, precisamente, a partir de considerações a respeito dessa concepção grega de poder (o poder que surge na ekklesia e se manifesta plenamente a partir do diálogo no espaço público) que Hannah Arendt analisa, em A Condição Humana (1999), o processo moderno que permite a transformação dos cidadãos em animais laborantes. Em outras palavras, Arendt identifica o movimento progressivo, que tem lugar nas sociedades modernas, de ocupação do espaço político pelo homo laborans, cujas atividades estão relacionadas à renovação do ciclo biológico do corpo humano. Assim, para a autora, a progressiva ocupação do centro da vida política pela vida laborante, biológica e natural, seria a responsável pela decadência do espaço público na sociedade moderna (Arendt, 1999; Agamben, 2014a). É possível encontrar em Arendt, então, uma perspectiva da política como atividade depurada daquilo que está ligado à manutenção da vida e que, portanto, não deve ocupar o espaço público moderno.

Apesar das contribuições originais de Hannah Arendt, o questionamento mais aprofundado sobre a articulação entre vida biológica e vida política, entre zoé e bíos, só teria início quase vinte anos depois, com as análises do filósofo francês Michel Foucault sobre a biopolítica. No movimento final do primeiro volume de História da Sexualidade, publicado em 1976 e intitulado A Vontade de Saber, Foucault (1999) discorre sobre o processo moderno através do qual a vida natural e biológica começa a ser incluída nos mecanismos e nos cálculos do poder estatal, transformando a política em biopolítica. A esse respeito afirmara Foucault que o "homem, durante milênios, permaneceu o que era para Aristóteles: um animal vivo e, além disso, capaz de existência política; o homem moderno é um animal, em cuja política sua vida de ser vivo está em questão” (1999, p. 134). Esse movimento em direção à vida biológica e política dos homens teria se iniciado, precisamente, na Europa da passagem do século XVIII para o século XIX quando emergiu o que Foucault qualificou como o problema das populações. As 
mudanças econômicas e sociais provocadas pelos inícios do capitalismo industrial produziram novos desafios para o governo das populações. Nesse momento, então, despontou uma nova governamentalidade, ou seja, um novo conjunto de técnicas ou táticas de governo simultaneamente direcionadas ao corpo individual - o "corpo máquina" (Foucault, 1999, p. 131) - e ao conjunto geral das populações.

O primeiro conjunto foi, para o filósofo, "assegurado por procedimentos de poder que caracterizam as disciplinas anátomo-política do corpo humano" (idem), visando manter a "utilidade e docilidade" de cada indivíduo localizado na massa. Foucault já havia trabalhado o dispositivo do poder disciplinar em cursos do Collège de France ministrados entre 1971 e 1974 e que levaram à escrita de Vigiar e Punir, publicado em 1975. Para Foucault, “a disciplina é o processo técnico unitário pelo qual a força do corpo é com o mínimo de ônus reduzida como força 'política', e maximizada como força útil" (1997, p. 194). Assim, nas instituições disciplinares - como a escola, o exército, o hospital, a fábrica e a prisão - cada indivíduo passou a ser adestrado, educado, condicionado a obedecer, reduzindo, ao máximo, sua capacidade de resistência, contestação e rebeldia. Ao mesmo tempo, as disciplinas aumentavam sua capacidade de atuar como corpo-máquina operando, precisamente, as máquinas da Revolução Industrial.

O segundo conjunto de técnicas a compor essa governamentalidade foi voltado, segundo Foucault, ao "corpo-espécie" (1999, p. 131), o conjunto geral das pessoas compreendidas como uma população viva portadora de dinâmicas próprias, como os ritmos de nascimento, morbidade, mortandade e enfermidades. Como um grande corpo vivo, essa reunião orgânica de pessoas passou a demandar políticas específicas, “toda uma série de intervenções e controles reguladores: uma biopolítica da população" (idem). Para Foucault, a governamentalidade contemporânea emergiu como a 
articulação de ações simultaneamente dirigidas para os indivíduos e para as populações, numa atualização de técnicas de gestão antigas na tradição ocidental e que remontam às procedências judaico-cristãs sintetizadas no que o filósofo nomeou como "poder pastoral": a metáfora bíblica fundamental que define a atenção individualizante do pastor/mestre voltada à saúde física/espiritual de cada ovelha/fiel e, ao mesmo tempo, a preocupação totalizante atenta às necessidades gerais do rebanho de ovelhas/fiéis (Foucault, 2003).

Na era da biopolítica das populações, desse modo, o Estado não seria apenas o agente a realizar a "potência de morte" de soberano sobre os súditos, mas o agenciador de múltiplas táticas destinadas à "gestão calculada da vida" (Foucault, 1999, p. 131). Diante do "fazer morrer" e "deixar viver", próprio das sociedades de soberania do Estado absolutista europeu, uma nova fase marcada pelo objetivo de "fazer viver" e "deixar morrer", ou seja, gerir as populações oferecendo um adicional de vida destinado à capacidade produtiva, mas acondicionado pelas disciplinas e pelo oferecimento de melhorias (higiênicas, educacionais, de planejamento urbano, laborais e, até mesmo, políticas) de modo a despotencializar resistências e rupturas.

Refletindo sobre essas contribuições de Foucault, Giorgio Agamben (2014a) destaca seus cursos no Collège de France que, a partir de 1977, passam a enfatizar a transformação do "Estado territorial" em "Estado de população", com o crescente aumento da importância da vida biológica como uma questão política, pertencente ao domínio do poder soberano, o qual também se transforma progressivamente em "governo dos homens".

Apesar de Agamben direcionar algumas de suas análises ao caso específico dos campos de concentração e das políticas de segurança produzidas pelas chamadas democracias liberais modernas, sua obra não pode ser compreendida como limitada a 
tal estudo empírico. Ao contrário, conforme a perspectiva adotada neste artigo aponta, a visão proposta pelo autor em homo sacer contribui para uma análise mais ampla e aprofundada da política ocidental moderna e sua construção sobre as bases do fenômeno da exceção e da inclusão da "vida nua" ou da "vida biológica" nos cálculos do poder. Talvez por isso seja necessário, nos termos deste artigo, uma abordagem da perspectiva foucaultiana a respeito da ligação simbiótica entre política e vida biológica.

Tanto Agamben quanto Foucault foram atentos às análises de realidades históricas e processos específicos, sem a pretensão de produzir teorias totalizantes e que pudessem ser automaticamente transportadas a outras realidades. No entanto, a dinâmica da biopolítica das populações, ainda que tenha emergido na Europa ocidental na passagem do século XVIII para o século XIX, também se fez presente com manifestações nas Américas

cerca de um século depois e em outras partes do globo, seguindo a expansão dos modelos político e econômico europeus. É desse modo, atento às especificidades e sem procurar tomar os escritos de Foucault e Agamben como "teorias gerais da política contemporânea", que caminharemos com algumas de suas sugestões de modo a estudar o caso particular das políticas de segurança atualmente em prática no Rio de Janeiro sob o signo geral da pacificação.

Nesse sentido, as análises de Agamben, ao mesmo tempo em que estão assentadas sobre algumas premissas levantadas previamente por Foucault sobre a inscrição da vida biológica na esfera política, também propõem algo novo: não o abandono total dos modelos jurídico-institucionais (teoria de soberania, teoria do Estado), mas a análise sobre o ponto oculto de interseção entre estes modelos e o modelo biopolítico do poder. Desse modo, o objetivo da pesquisa de Agamben não é propriamente "liberar-nos (...) do privilégio teórico da lei e da soberania" (Foucault, 
1999, p. 87), nem se abster de elaborar uma teoria sobre a legitimação do poder estatal, mas antes investigar o ponto em que modelo jurídico-institucional e modelo biopolítico do poder se tocam, apresentando como um dos resultados de sua investigação a proposição de que ambas as análises referentes a tais modelos são inseparáveis. Assim, a pesquisa de Agamben propõe que a inscrição da vida natural e biológica na esfera política constitua o núcleo originário, ainda que encoberto, do poder soberano. A partir disso é possível afirmar que "a produção de um corpo biopolítico seja a contribuição original do poder soberano. A biopolítica é, nesse sentido, pelo menos tão antiga quanto a exceção soberana" (Agamben, 2014a, p.14).

Agamben torna a "vida nua", isto é, a vida exterminável do homo sacer, um dos pontos-chave de sua obra. Para o autor (Agamben, op.cit., p.16), o homo sacer é "uma obscura figura do direito romano arcaico, na qual a vida humana é incluída no ordenamento unicamente sob a forma de sua exclusão (ou seja, de sua absoluta matabilidade) (...) que constitui o primeiro paradigma do espaço político do Ocidente". Agamben propõe, então, uma visão diferenciada daquela de Foucault ao afirmar que o que caracteriza a política moderna não é tanto a inclusão da zoé na pólis, já indicada pelos textos sacros da soberania, nem o fato de que a vida biológica vem se tornando um objeto eminente dos cálculos de poder. Para Agamben, o fator decisivo do espaço político moderno é, sobretudo, o processo pelo qual “a exceção se torna em todos os lugares a regra" (idem), processo esse que se desenvolve de modo análogo à coincidência entre o espaço político e o espaço da vida natural e biológica, em uma “zona de irredutível indistinção" (idem) entre bíos e zoé.

Sem objetivar o detalhamento das diferentes perspectivas teóricas expressas por Foucault e Agamben a respeito da dupla categorial vida biológica/vida política, que ambos concordam ser um dos pilares fundamentais da política moderna, a presente reflexão 
fundamenta-se na contribuição de Agamben no tocante ao "campo" como a materialização da exceção e na possibilidade de compreender, a partir disso, suas metamorfoses que, nos termos deste trabalho, assumem a forma de certas favelas e regiões da cidade do Rio de Janeiro. Nas palavras de Agamben, “o estado de exceção, que era essencialmente uma suspensão temporal do ordenamento [jurídico], torna-se agora uma nova e estável disposição espacial, na qual habita aquela vida nua que, em proporção crescente, não pode mais ser inscrita no ordenamento" (Agamben, op.cit., p.171). Assim, para esse autor, se antes havia um "ordenamento sem localização" (o estado de exceção, no qual a lei é suspensa), agora há uma correspondente "localização sem ordenamento" (o campo, como espaço permanente de exceção) (idem). É, então, a partir de tal perspectiva, que se faz uso aqui da noção de "espaços" de exceção.

Assim, com essa perspectiva, a presente reflexão buscará compreender o caso empírico da atuação das forças de segurança pública em certas favelas e regiões da cidade do Rio de Janeiro, nas quais existem Unidades de Polícia Pacificadora (UPP) da Polícia Militar estadual, desde 2008, e nas quais houve a presença das Forças de Pacificação do Exército Brasileiro (entre 2010 e 2012 nos Complexos da Penha e do Alemão e, entre 2014 e 2015, no Complexo da Maré). O objetivo geral é analisar a existência de uma relação entre a política de segurança pública do Rio de Janeiro, implementada pelas UPP, com a participação federal por meio do Exército Brasileiro, e a produção de "espaços" de exceção (intencionalmente plurais e localizados) que funcionam sob a dupla categorial vida biológica/vida política, zoé/bíos. Buscar-se-á analisar, com isso, a construção do "campo" nesses espaços da cidade do Rio de Janeiro, entendendo esse termo a partir da perspectiva de Agamben (2014a, p.164), a saber: “o espaço que se abre quando o estado de exceção começa a tornar-se a regra". 
A estrutura do campo é montada, nesse sentido, a partir da realização permanente e normal da exceção. Cabe ressaltar que a presente análise salienta a localização do atual regime de exceção produzido pela política de segurança pública, o qual fica restrito a espaços determinados, nos quais há a suspensão de uma série de direitos civis e a atuação das forças coercitivas como ator soberano. Nesses "espaços" de exceção, "a política torna-se biopolítica e o homo sacer se confunde virtualmente com o cidadão" (Agamben, op.cit., p.167).

\section{Uma lente analítica: discursos de (in)segurança e “espaços” de exceção}

O discurso de (in)segurança que pauta o espaço urbano da modernidade pode ser compreendido a partir da lógica da construção da "sociedade do bode expiatório" (Beck, 2011, p.92), na qual pessoas ou grupos são convertidos em culpados pela desestabilização da ordem interna, não porque se constituam de fato como uma ameaça à segurança, mas porque são construídos dessa forma através de discursos e ações políticas. Conforme afirma o autor, "nas situações de ameaça, é a consciência que determina a existência. O conhecimento adquire uma nova relevância política" (Beck, op.cit., p.28). Há, com isso, a construção de elementos "indesejáveis", que passam a ser vistos como fonte de insegurança e instabilidade que precisam ser gerenciadas por algum tipo de política de segurança pública, tendo em vista o seu controle e a prevenção de possíveis riscos que possa trazer ao espaço social.

Sob essa óptica, o emprego de um discurso de (in)segurança pública permite que pessoas ou grupos determinados sejam vistos como ameaças à ordem doméstica estabelecida, com a respectiva construção do espaço social a partir da lógica binária amigo/inimigo, pacífico/ameaça, produzindo, com isso, verdadeiros "espaços" de 
exceção (intencionalmente plurais e localizados). Em sua palestra intitulada "Security and Terror" (2001), Agamben traça um paralelo entre a lógica governamental da segurança, a exceção e a crise da atual democracia liberal: medidas de segurança requerem uma referência constante ao estado de exceção e, assim, no longo prazo, acabam sendo irreconciliáveis com os elementos tradicionais da democracia liberal.Em artigo mais recente, intitulado "Como a obsessão por segurança muda a democracia" (2014b), Agamben reitera essa perspectiva afirmando que o rótulo da "segurança" acaba funcionando como um argumento de autoridade que, ao colocar uma questão acima do debate público, permite a adoção de medidas emergenciais e excepcionais que anteriormente seriam inaceitáveis, numa acepção muito próxima àquela que Buzan, Wæver e De Jaap (1998) denominaram como "securitização", ou seja, o processo pelo qual um determinado tema ou questão é definido como uma "ameaça existencial" ao Estado, aos indivíduos ou à sociedade por meio de discursos de segurança que encontram ressonância numa audiência específica (no caso, a sociedade como um todo), autorizando que o Estado agencie táticas de salvamento geral que suspendem direitos e garantias das democracias liberais. Nesse sentido, segundo a visão agambeniana consoante com a da "securitização" - o Estado, ao se colocar sob o signo da segurança, fragiliza a democracia e se afasta do domínio da política, uma vez que democracia e vida política são, na tradição ocidental, sinônimos.

A fim de compreender, na chave agambeniana, a construção do espaço social sob a lógica do "inimigo interno" e, com isso, a reprodução de "espaços" de exceção, tornase necessário analisar a discussão sobre excepcionalidade a partir da contribuição teórica de Carl Schmitt, Walter Benjamin, além do próprio Giorgio Agamben. O debate que se estabelece nesse contexto se dá pelas posições antitéticas assumidas por Schmitt e Benjamin, as quais são interpretadas por Agamben (2004) como uma "luta de gigantes" 
que ilustra a oposição entre violência e direito. É este, então, o ponto de partida que permite as críticas e contribuições significativas que Agamben oferece ao tratamento teórico da questão da exceção, com sua posterior aplicabilidade aos temas de segurança que "invadem" a agenda das democracias liberais, ensejando um tipo de ordenamento político localizado em um "patamar de indeterminação entre democracia e absolutismo" (Agamben, 2004, p.13).

Para o jurista e teórico alemão Carl Schmitt, a essência da política - o que ele chama de "o político" - está na relação amigo/inimigo. Esta distinção denota o grau mais intenso de união ou separação e funciona como um dos critérios elementares da política, uma vez que é de acordo com esta antítese que as nações se agrupam (Schmitt, 1996). Nesse contexto, o Estado, representado na figura do soberano, assume a posição de entidade política decisiva: é ele o responsável pela distinção amigo/inimigo, pela declaração de guerra e pela decisão sobre a exceção (Schmitt, op.cit.). No que diz respeito a este último aspecto, Schmitt percebe a exceção como um evento singular, pois é uma situação que ameaça a existência do Estado e não pode ser tratada através das normas e regras do ordenamento político padrão (Agamben, 2004). Assim, para Schmitt, a exceção abarca qualquer tipo de distúrbio que demanda a aplicação de medidas extraordinárias (Schmitt, 1985). Nessa perspectiva, como a natureza da exceção não pode ser prevista pela ordem jurídica existente, o soberano assume a função de decidir sobre a exceção. Tem-se, nesse sentido, a soberania como o lugar da exceção, a partir do qual a concentração de poderes no soberano se revela de maneira mais absoluta, com a emergência de decisões que não estão pautadas pelos constrangimentos típicos das Constituições liberais.

Tanto Walter Benjamin quanto Giorgio Agamben criticam a percepção schmittiana da soberania como um fenômeno político existente apenas no extremo da 
exceção, ao passo que ressaltam que este "evento singular" teria se tornado a regra (Benjamin apud Agamben, 2004), passando a funcionar como um paradigma de governo que representa não mais do que uma forma de legitimar o arbítrio do Estado contra o cidadão. Nessa perspectiva, então, soberania e exceção se unem para fornecer revestimentos legítimos para práticas de poder que, sob o argumento de defesa do Estado, deslocam medidas provisórias e excepcionais como técnicas de governo. Mais do que isso, Agamben afirma que a exceção é a resposta schmittiana à perspectiva de Benjamin acerca da existência de uma violência pura, sem nenhuma ligação com o direito e, portanto, inteiramente anômica e revolucionária. Nesse sentido, a fim de negar a existência desse tipo de ação política, Schmitt procura garantir a relação entre o contexto anômico e o contexto jurídico, utilizando-se para isso do conceito de decisão que se manifesta pelo poder soberano e o une à exceção ${ }^{1}$.

Em contraposição à perspectiva schmittiana, Agamben procura demonstrar que a exceção, mais do que um "evento singular", tornou-se um paradigma contemporâneo de governo, o que permite a compreensão das atuais políticas de segurança adotadas pelas democracias liberais (mas que não se restringe a elas). Para esse autor, os procedimentos de exceção visam uma ameaça imediata e real, que deve ser eliminada ao se suspender por um período limitado as garantias da lei. Entretanto, os dispositivos de segurança contemporâneos constituem, ao contrário, uma técnica de governo normal e permanente que faz referência constante a políticas de exceção. Agamben reafirma, assim, a perspectiva de que a política contemporânea tem transformado uma medida aparentemente provisória e excepcional em um paradigma de governo. Nesse contexto, “o estado de exceção ameaça converter-se em normalidade” (Beck, 2011, p.28). Em

1 De início, a exceção parece situar-se em um lócus fora da ordem jurídica existente, tendo em vista sua natureza. Entretanto, ao estabelecer o soberano como aquele que decide sobre a exceção, Schmitt (1985) ancora a exceção na ordem jurídica, afirmando, paradoxalmente, a superioridade do soberano no que diz respeito à norma e seu pertencimento ao sistema legal. 
outras palavras, "o estado de exceção cessa, assim, de ser referido a uma situação externa e provisória de perigo factício e tende a confundir-se com a própria norma" (Agamben, 2014a, p.164).

Na perspectiva de Agamben (2000), quando o estado de exceção se torna um paradigma de governo, isto é, quando uma medida provisória e excepcional se transforma em regra e em técnica para a gestão política das pessoas, abre-se espaço para a materialização do "campo", que se constitui como um espaço de exceção permanente. A fim de compreender com necessária clareza a construção desses espaços de exceção é preciso, então, saber o que Agamben define como “campo".

Ao perguntar-se "o que é um campo?", o filósofo italiano estava interessado em analisá-lo não como um fato histórico ou uma anomalia pertencente ao passado, mas como o nomos do espaço político em que ainda vivemos (Agamben, 2000). Na tentativa de responder ao seu próprio questionamento, Agamben salienta que os campos não nasceram da lei ordinária, mas sim do estado de exceção e da lei marcial. Para esse autor, então, a essência do campo consiste na materialização do estado de exceção e na consequente criação de um espaço onde a "vida nua" tem lugar, sendo preciso admitir a existência do campo sempre que esta estrutura é montada, independentemente da natureza dos crimes cometidos e dos criminosos que o campo deve recolher (Idem). Como exemplo dessa estrutura, Agamben (2014a) cita desde o caso das zones d'attente nos aeroportos internacionais, onde os solicitantes de refúgio são detidos, até "certas periferias de nossas cidades" (idem, p.171).

A perpetuação da prática política de construção do campo permite, assim, a abertura de um espaço de exceção no qual a ordem jurídica é suspensa e violências que podem ou não ser cometidas não mais dependem de algum aparato legal e normativo, mas apenas da civilidade e do senso ético da polícia, que passa a atuar temporariamente 
como soberano ${ }^{2}$ (Idem). Nesses espaços, os indivíduos são reduzidos à "vida nua", expressão usada por Agamben (2014a) a fim de identificar a vida exterminável do homo sacer, isto é, aquela vida que pode ser eliminada por qualquer um, sem que isso signifique a perpetração de algum crime ou violação. Nesse sentido, o homo sacer pode ser compreendido como alguém que é forçosamente reduzido à "vida nua", isto é, à vida não-política e não-social.

Agamben, a partir da sua reflexão sobre a distinção aristotélica entre zoé e bios, argumenta, então, que a zoé (a vida natural dos homens) é incluída no campo da política através do estado de exceção e da sua materialização sob a forma do campo. Nesse espaço determinado não é mais possível distinguir entre a vida biológica e a vida política, tornando possível o arbítrio do Estado sobre a vida que pode ser exterminada, mesmo que não se tenha cometido nenhum crime específico. O cidadão tem, assim, sua vida natural incluída na esfera política, tornando-se alvo aberto à violência estatal. Nesse sentido, as pessoas ou grupos que se encontram "incluídos pela sua exclusão", conforme afirma Agamben, submetidos ao arbítrio de instâncias superiores nesses espaços de exceção, nos quais a lei é suspensa, tornam-se passíveis de variadas formas de violência em um território que, paradoxalmente, está situado fora da ordem jurídica normal do Estado.

Cumpre ressaltar que, em Homo Sacer (2014a), Agamben não faz referência à exceção como um momento pontual, como uma declaração de um estado excepcional. Pelo contrário, o "estado de exceção" ao qual o autor se refere está diretamente conectado ao próprio poder soberano e dificilmente se distingue do estado normativo, assim como afirmara Walter Benjamin. Não há, assim, um momento específico em que determinadas classes ou grupos de cidadãos são transformados em homo sacer: a

2 Conforme afirma Arendt (2012), o Estado da lei ameaça transforma-se gradualmente em Estado policial, com o poder arbitrário da polícia crescendo vertiginosamente. 
inclusão da vida nua no jogo político é, para Agamben, o núcleo originário do poder soberano: “o estado de exceção, no qual a vida nua era, ao mesmo tempo, excluída e capturada pelo ordenamento, constituía, na verdade, em seu apartamento, o fundamento oculto sobre o qual repousava o inteiro sistema político [...]" (Agamben, 2014a, p.16). Sob esta perspectiva, a vida nua de todo cidadão é, potencialmente, o novo corpo biopolítico da humanidade e a esfera soberana caracteriza-se justamente pela possibilidade de matar sem cometer homicídio e sem celebrar um sacrifício, o que faz do homo sacer a vida que é capturada nessa esfera. É também dessa forma que a vida humana se politiza: através da sua exposição constante a um poder incondicionado de morte. Afirma Agamben que “a grande metáfora do Leviatã, cujo corpo é formado por todos os corpos dos indivíduos, deve ser lida sob esta luz. São os corpos absolutamente matáveis dos súditos que formam o novo corpo político do Ocidente" (Agamben, 2014a, p.122).

Desta estrutura complexa que fundamenta o poder soberano, nasce o que chamamos aqui de espacialização da exceção ou, em outras palavras, a criação do campo como o espaço biopolítico por excelência: “o nascimento do campo em nosso tempo surge, então, nesta perspectiva, como um evento que marca de modo decisivo o próprio espaço político da modernidade" (Agamben, 2014a, p.170). Ora, se temos no Brasil um estado de exceção tornado indiscernível do estado normativo, no qual os corpos de pobres e favelados estão sujeitos, mais do que os corpos de outros cidadãos, ao poder soberano de decretar sua morte sem que isso constitua um crime, temos também nas favelas uma versão local do espaço biopolítico que se abre a partir deste processo.

Nesses "espaços" de exceção ou, mais especificamente, no "campo", a suspensão temporal do ordenamento jurídico devido a uma suposta situação de perigo adquire uma disposição espacial permanente que, de forma paradoxal, encontra-se fora do 
ordenamento normal (Agamben, 2014a). A fim de compreender melhor tal argumento, Agamben propõe algumas considerações relevantes sobre "o estatuto paradoxal do campo enquanto espaço de exceção" (idem, p.165). Segundo o autor, o campo é "um pedaço de território que é colocado fora do ordenamento jurídico normal, mas não é, por causa disso, simplesmente um espaço externo". Aquilo que nele é excluído é “capturado fora, incluído através da sua própria exclusão” (idem, p.166). Tem-se, assim, um espaço em que a lei é suspensa e no qual a distinção entre fato e direito torna-se nebulosa. Aqueles que se encontram nesse espaço foram despojados, segundo Agamben, de todo estatuto político e reduzidos, com isso, à "vida nua". Torna-se possível afirmar, nesse sentido, que “o campo é também o mais absoluto espaço biopolítico que jamais tenha sido realizado, no qual o poder não tem diante de si senão a pura vida sem qualquer mediação" (Agamben, 2014a, p.167). Assim, a partir dessas noções é que se pretende esboçar uma análise do caso das Unidades de Polícia Pacificadora no Rio de Janeiro (UPP) e das Forças de Pacificação em espaços seletivamente escolhidos da capital fluminense.

\section{A exceção em prática: as pacificações no Rio de Janeiro}

As favelas nas quais hoje existem as Unidades de Polícia Pacificadora (UPP) são a configuração contemporânea de um fenômeno de ocupação urbana iniciado no final século XIX quando morros próximos à região central da então capital federal começaram a ser ocupados por migrantes de regiões interioranas expulsos por condições econômicas extremamente severas e, por vezes, como no caso dos nordestinos, de penúria material associada às agruras climáticas da seca. Segundo Valladares (2005), a construção da imagem das favelas que se fez, nos anos iniciais do 
século XX, marcou as interpretações posteriores sobre essa modalidade de ocupação espacial no Rio de Janeiro, imprimindo significações que foram desde a visão das favelas como "regiões rurais" introduzidas no seio da cidade, até as mais duradouras atribuições da favela como espaço de doenças, degeneração, vadiagem e criminalidade.

Dentre o que Valladares chama de "mitos de origem" das favelas cariocas, conectam-se versões de difícil comprovação que registram ao menos parcialmente a história dos seus habitantes e suas procedências. Dentre essas narrativas, destaca-se a que foca nos soldados que retornavam vencedores da Guerra dos Canudos ao Rio de Janeiro e que, não recebendo as terras que lhes foram prometidas pelo governo ao se juntarem às Forças Armadas, começaram a ocupar um cerro no Centro do Rio, hoje o Morro da Providência, batizando de favela em referência a uma planta abundante nas colinas onde acampavam nos arredores do arraial de Canudos (Lima, 2012). Autores como Leite (2012), além de Valladares, sugerem cuidado ao reconstituir o “início” das favelas no Rio de Janeiro a partir deste mito de origem, evitando localizar uma verdade absoluta desse começo.

As favelas, crescidas sem o controle disciplinar do Estado, constituíram-se como espaços de ocupação inventivos nos quais foram desenvolvidas formas próprias de vida econômica e comunitária, assim como modalidades singulares de autoridade política e coercitiva vinculadas a grupos dedicados a um grande número de atividades legais e ilegais que emularam, parcialmente, funções caritativas das igrejas e das sociedades filantrópicas e assistenciais e repressivas do Estado (Serra e Rodrigues, 2014). Isso não significa que as favelas surgiram de forma desconectada da presença estatal. Ao contrário, houve sempre uma relação estabelecida por simbioses entre o poder político constituído e a vida comunitária na favela, numa forma de gestão local dos ilegalismos e do cotidiano desses bairros estritamente conectados com a vida da cidade formal 
(Souza, 2008).

Não obstante, a relação das forças do Estado com as favelas foi marcada historicamente pelo autoritarismo e coerção, ora visando a fins higienistas (para a contenção de doenças ou insalubridades) ou, de forma violenta e ostensiva, pelas mãos da polícia, sob a justificativa de combater o crime. O Estado, portanto, não é ausente das favelas. Sua presença, no entanto, se deu menos pelo oferecimento de serviços públicos e de infraestrutura, com respeito aos direitos e à cidadania, e mais pela contenção coercitiva das populações associada a práticas clientelistas vinculadas à vida políticopartidária.

É importante ressaltar, portanto, que as favelas estabeleceram historicamente relações singulares com agentes do chamado "poder público" e da economia legal por meio de uma série de práticas nos limites entre a legalidade e a ilegalidade. Bolsões de autoridade paralela foram constituídos, principalmente a partir da entrada em cena da economia da cocaína nos anos 1980, e as favelas e seus moradores passaram a ocupar, ao lado de instituições como as prisões, o imaginário social como imagens do medo, nos quais habitavam pessoas perigosas, criminosas, ameaçadoras da ordem (Rodrigues, 2015). O morador da favela, seguindo uma lógica própria ao racismo disseminado na sociedade brasileira e institucionalizado nas políticas de segurança pública e de seguridade social, foi sistematicamente ora identificado como o agente do crime e do perigo (à propriedade e à vida), ora despido de seu caráter político, restando-lhe apenas seu aspecto biológico, o que o torna descartável, exatamente como um animal inferior.

Como citado acima, a partir dos anos 1980, a economia ilegal das favelas passou a ser crescentemente articulada em torno do tráfico de drogas ilegais que, naquela década, despontava como um importante negócio clandestino no Brasil (Arias, 2006). As favelas, notadamente as localizadas nas regiões centrais e sul do Rio de Janeiro, passaram a ser 
importante entrepostos comerciais para o mercado ilícito das drogas, por serem essas as áreas de maior concentração de consumidores. A disputa por territórios é tão vital num negócio ilícito quanto na economia legal. No entanto, o ambiente de ilegalidade propicia uma competição violenta pela conquista e manutenção de espaços que servem tanto como base para a recepção e preparo para a venda das drogas ilícitas quanto como zonas seguras para os membros do grupo narcotraficante. Desse modo, o varejo do narcotráfico tende a ser, historicamente, mais violento do que a etapa da grande distribuição internacional, geralmente controlada por organizações transterritoriais que manejam quantidade vultosa de dinheiro e dão preferência a arranjos e acordos com outras organizações e autoridades estatais (Krauthausen e Sarmiento, 1991).

No Rio de Janeiro, a violência do setor varejista colocou em confronto jovens pobres, na sua maioria negros e procedentes das favelas situadas nas encostas dos morros que margeiam bairros de classe média e alta. As trocas de tiros entre grupos narcotraficantes e os eventuais embates com policiais durante incursões nas favelas tornaram-se, assim, muito visíveis para uma parcela da população carioca ciosa da sua segurança pessoal e da proteção dos seus bens materiais. A visibilidade da "guerra entre morros" celebrizou traficantes e transformou grupos como Comando Vermelho e Terceiro Comando, ainda nos anos 1980, e Amigo dos Amigos, já a partir dos anos 1990, em nomes e siglas conhecidos e temidos em todo Brasil. As políticas de segurança pública elaboradas pelo governo estadual passaram, então, a objetivar modos de conter a violência nas favelas, já que a cidade é considerada pelo Estado brasileiro como um cartão de visitas do Brasil, fazendo dela "the country's security laboratory and 'shop window' to the world" (Amar, 2009, p.513).

De iniciativas mais voltadas à inclusão e urbanização de favelas, notadamente durante os governos de Leonel Brizola (1983-1987 e 1991-1994), às mais centradas no 
aspecto repressivo voltado à contenção das populações das favelas, a relação entre o Estado e as favelas, seus moradores e membros dos grupos narcotraficantes passou a registrar maiores tensões e violências. A fim de conter a violência que se alastrava dentro dessas comunidades e de incluí-las socialmente, diversas alternativas foram propostas ao longo da década de 1990, como o programa Favela-Bairro, visando à urbanização de "comunidades". Como essas soluções não apresentavam os resultados esperados e com os surtos de violência ocorridos no estado durante os anos 2000, uma alternativa foi elaborada para resolver o problema. Entretanto, ela ainda estava impregnada com a ideia de que uma "guerra" de fato estava sendo travada e que o inimigo seria o narcotraficante.

Nota-se que a palavra guerra tem um significado extremamente forte. No senso comum, violências incomensuráveis podem ser cometidas numa "guerra", pois a ameaça representada pelo inimigo é tida como excepcional. Esse uso banalizado da expressão "guerra" foi historicamente utilizado com os mais diversos propósitos, incluindo a "guerra contra o crime" em geral e contra "as drogas" em particular, como atesta a expressão war on drugs, lançada pelo governo de Richard Nixon, em 1971, para designar a repressão frontal à produção e tráfico de psicoativos ilícitos que os EUA pretendiam sustentar a partir de então (Rodrigues, 2012).

Lembrando a já mencionada noção de "securitização" é possível ter em mente que a ideia de uma "guerra" lançada contra "ameaças" faz parte da prática corriqueira dos Estados em seu trabalho de acionar meios coercitivos para controlar populações específicas ou para reforçar a autoridade central a partir de medidas excepcionais repressivas (Buzan, Wæver e De Jaap, 1998). É possível acordar-se que o direito internacional, especialmente a partir das iniciativas internacionais tomadas desde o final do século XIX, procurou "humanizar" a guerra e, no limite, conter suas violências, 
protegendo civis e militares feridos (Rodrigues, 2010). No entanto, a prática da "guerra" e o conceito de "inimigo" habitam o campo da hostilidade contra o "ameaçador", quer seja ele um estrangeiro em armas num exército regular ou um "perigo doméstico" representado pelo imigrante, pelo pobre, por uma minoria ou por criminosos.

Associada à noção de "guerra" está a de "inimigo" e, com isso, a possibilidade - e mesmo aceitação ou normalização - da eliminação física daquele que ameaça. No que diz respeito especificamente aos narcotraficantes das favelas cariocas há uma sobreposição de imagens ameaçadoras que foram reforçadas pela associação com o narcotráfico. No entanto, antes de serem narcotraficantes, esses homens e mulheres são negros, pobres, muitos deles migrantes ou filhos de migrantes do Nordeste brasileiro ou do interior nacional. A estigmatização como "traficantes", portanto, foi adicionada e reforçou os estereótipos já existentes e que marcam esses corpos. A criminalização de muitas drogas e, consequentemente, a existência de um grande negócio ilegal, fez com que essas pessoas, tradicionalmente visadas pelo poder coercitivo, pudessem ser ainda mais perseguidas, aprisionadas e mortas. E parte substancial dessas pessoas vive em favelas ou periferias.

É importante ressaltar que os narcotraficantes não possuem um uniforme, nem um perfil específico que facilite sua identificação, como ocorre em situações de guerra convencional, em que os dois oponentes se reconhecem tanto pelas suas bandeiras quanto por seus uniformes. A suposta "identificação" do narcotraficante passa pelos estereótipos do negro, pobre e morador de favela. Como esses alvos são indiscerníveis dos habitantes das favelas, a "guerra ao tráfico" se transforma numa "guerra às favelas", pois as políticas de segurança pública tipificam esses territórios como violentos per se (Leite, 2014), como o local onde estes traficantes "habitam naturalmente".

Como aponta Almendra (2014), ainda que a mídia não seja a responsável pela 
opinião pública, ela ainda assim possui influência na constituição de imagens e juízos. Como exemplo, pode-se citar a divulgação de uma notícia, em maio de 2015 no site do jornal O Dia, sobre jovens de classe média presos na Tijuca, bairro da Zona Norte da cidade, com trezentos quilos de maconha ${ }^{3}$. Conquanto a notícia mencione que eles poderiam estar envolvidos com o tráfico de drogas na Zona Norte da cidade, a manchete os considera somente como jovens de classe média que portavam drogas e não como "traficantes". A distância entre essa imagem atribuída a jovens de classe média e a de jovens negros ou mulatos habitantes de favelas é bastante evidente. Ainda de acordo com Almendra, a questão da "violência urbana" não é uma representação apenas criada pela mídia. Mais do que isso, ela é fruto de experiências cotidianas relacionadas ao medo e à sensação difundida de perigo ou ameaça (Almendra, 2014). Por fim, o autor ressalta que os relatos na mídia sobre as UPPs devem ser entendidos como moldados a partir de percepções sociais generalizadas sobre violência urbana e segurança pública.

Nessa lógica, pode-se compreender a produção de uma imagem da favela como um local de "barbárie" e violência, habitada por indivíduos a ser controlados e que representam um perigo para os habitantes da cidade formal. Oliveira (2014) destaca que no imaginário daqueles responsáveis pela formulação de políticas públicas, os morros são tidos como territórios do inimigo e seus habitantes como "colaboradores" tão moralmente duvidosos quanto os traficantes, que, por isso, não podem - e muitas vezes também não devem - ser distinguidos claramente dos criminosos.

Por conta desta "guerra às drogas" acoplada a uma mais ampla "guerra às favelas", todo morador dessas localidades, especialmente os homens e mulheres jovens, pode ser considerado um "inimigo" e, como inimigo na prática da guerra (e não nos

3 Notícia disponível em < http://odia.ig.com.br/noticia/rio-de-janeiro/2015-03-27/jovens-de-classe-media-saopresos-com-300-quilos-de-maconha-na-tijuca.html> Acesso em 4 ago 2015. 
textos do direito humanitário), pode ser tratado com violência, sem respeito à sua dignidade e, no limite, poder ser eliminado fisicamente. Isso porque, em consonância com o analisado por Agamben a partir de sua crítica a Schmitt, o inimigo representa uma ameaça grave à ordem política e econômica, além de constituir um perigo a um dado modo de vida. Esse perigo, como mencionamos anteriormente, pode ser tanto um ator externo, um outro Estado, quanto um ator interno (o "traficante", por exemplo). Nesse sentido, o Estado possui a prerrogativa de suspender os direitos destes cidadãos em prol da manutenção de seu controle sobre uma fração do território.

As violações de direitos daí decorrentes são consideradas válidas e justas por grande parte da mídia e da sociedade, exatamente por causa do discurso, disseminado e incentivado entre eles, de que a favela e seus moradores são figuras de segunda classe na vida política da cidade. De acordo com Oliveira (2014), a partir dos anos 1990, as favelas deixaram de ser entendidas como o "berço do samba" ou "curral eleitoral" para serem tidas como territórios controlados pelos traficantes, causa da insegurança e violência na cidade separada entre o formal "de bem" e o informal violento. Esse tipo de associação exaustivamente repetida e incentivada pela mídia funciona como justificativa para a "metáfora da guerra" (Leite, 2012) e a necessidade do combate deste problema por meios militarizados.

É nesse contexto que em 2008 foi implementada a primeira Unidade de Polícia Pacificadora do Rio de Janeiro, no Morro Santa Marta, criada oficialmente em 2009 pelo Decreto nº 41.450 (Lima, 2012; Rodrigues, 2012). De acordo com o site da Secretaria de Segurança Pública estadual sobre o programa de pacificação, a Unidade de Polícia Pacificadora consiste em "parcerias entre os governos (...) e diferentes atores da sociedade civil organizada e tem como objetivo a retomada permanente de 
comunidades dominadas pelo tráfico" ${ }^{4}$. As fases da operação podem ser brevemente resumidas nas seguintes: investigações e operações de inteligência a fim de desarticular o tráfico na região a ser ocupada; incursão no território para reconquista por tropas especial da PM, com destaque para o Batalhão de Operações Especiais (BOPE); instalação de fato da UPP, com a fixação de bases permanentes e alocação de forças de segurança que agem especificamente nestas regiões; (re)tomada do controle do Estado com a execução de medidas sociais, como a criação de escolas, postos de saúde e centros de cultura, entre outros.

De acordo com Cabeleira (2013), a utilização das UPPs é a forma que o governo do Rio de Janeiro encontrou para consolidar a pacificação da cidade. É importante ressaltar, ainda segundo Cabeleira (2013), que esta nova política pública ocorre juntamente com a preparação dos megaeventos que ocorrerão na cidade. Por conta deles, diversas obras de planejamento urbano estão sendo realizadas na cidade que se estendem dos morros ao porto, como a obra Porto Maravilha (Cabeleira, 2013). Essas intervenções urbanísticas atraem interessados em investir em locais próximos a essas áreas que receberão os eventos, concentradas no Centro, Zona Sul e Zona Norte da cidade $^{5}$, gerando especulação imobiliária e processos de gentrificação (expulsão econômica de moradores diante do aumento do preço dos aluguéis e dos serviços). Coincidentemente, a maior parte das quarenta e duas UPPs implantadas até dezembro de 2015 na cidade está localizada na Zona Sul e na Zona Norte. Na Zona Norte, por sua vez, as UPPs concentram-se nos bairros de ocupação mais tradicionais de classe média Tijuca, por exemplo - e nas favelas que são cortadas pelas vias de acesso rodoviário ao

4 A descrição completa pode ser encontrada em $<$ http://www.upprj.com/index.php/o_que_e_upp $>$. Acesso em 4 ago 2015.

5 A lista com as localidades de todas as UPPs implantadas no Rio de Janeiro pode ser encontrar em $<$ http://www.upprj.com/index.php/historico>. Acesso em 4 ago 2015. 
Rio (a Linha Vermelha e a Via Dutra), como os complexos do Alemão, da Penha e da Maré, este último vizinho do Aeroporto Internacional do Galeão (Rodrigues e Serra, 2014; Souza, 2015).

A associação da pobreza com a criminalidade e a violência faz com que as favelas sejam vistas de forma negativa, como focos para o transbordamento de atividades ilegais e de ações violentas. Nesse sentido, a transformação do Rio de Janeiro em uma "cidade de negócios" que atraia investidores e que seja capaz de abrigar os megaeventos que ocorrerão na cidade exige que se executem as medidas consideradas necessárias dentro destas localidades para conter e controlar a "violência urbana", fator que "mancha" a imagem da cidade e pode impedir seu desenvolvimento no termos de um capitalismo globalizado e de especulação financeira e imobiliária (Almendra, 2014).

Além das UPPs, em alguns casos, como na Penha e no Alemão, as Forças Armadas foram utilizadas tanto na primeira fase da operação quanto na consolidação do controle territorial. Esta utilização é permitida na legislação como operações de Garantia da Lei e da Ordem (GLO) previstas a partir do Art. 142 da Constituição Federal (1988) e de leis complementares que vieram detalhar regras e procedimentos para essas operações: Lei Complementar no 97 (1999), Decreto nº 3897 (2001) e Lei Complementar no 117 (2004). Passo fundamental, no entanto, foi a assinatura da Lei Complementar 136, de agosto de 2010, que deu base jurídica para que, em novembro desse mesmo ano, o governo estadual do Rio de Janeiro solicitasse apoio do governo federal para a ocupação da Vila Cruzeiro, favela pertencente ao Complexo de Favelas da Penha e das favelas vizinhas do Complexo do Alemão.

Em novembro de 2010, com o apoio de blindados da Marinha do Brasil e de membros da Polícia Federal e da Polícia Federal Rodoviária, tropas da Polícia Militar, incluindo soldados do BOPE, invadiram a Vila Cruzeiro após uma série de ações 
violentas (queima de veículos e tiroteios) atribuídos a uma facção do Comando Vermelho ali baseada. Diante da fuga de parte dos traficantes - registrada em imagens televisivas - e do grande apoio popular atingido frente à mobilização de blindados e de concentradas tropas da PM, a ação foi estendida para ocupar, também, o Complexo do Alemão. Para tanto, o governo estadual solicitou a presença do Exército Brasileiro. Foi, então, constituída pelo Ministério da Defesa a Força de Pacificação composta por tropas do exército, muitos com experiência prévia no componente militar da Missão das Nações Unidas para a Estabilização do Haiti (MINUSTAH), mantida pela ONU, desde 2004, no país caribenho (Rodrigues, 2012a).

A legislação específica sobre o emprego de forças federais foi acompanhada, no caso específico das Forças de Pacificação, de um regulamento próprio, as Regras de Engajamento e Instruções para o Emprego das Forças Armadas no Rio de Janeiro, que são passadas a todos que integrarão a Força de Pacificação, juntamente com o treinamento específico e cujo teor remete às Rules of Engagement das Nações Unidas, sob as quais os militares brasileiros atuam no Haiti (Rodrigues, 2012a). Nas Instruções, toma-se o cuidado de afirmar a vigência do estado de direito e a observância dos preceitos legais vigentes no país. Isso implica no reconhecimento de que a população não deve ser tratada como inimigo ou com hostilidade desnecessária. O documento também explicita que a força só deve ser utilizada em último caso respeitando os limites da proporcionalidade. Além disso, foram previstos formas de julgamento e punição para os integrantes da Força que cometessem, durante a operação, crimes previstos no direito penal e nos códigos de conduta militar.

Não obstante, é importante ressaltar que as Instruções trazem - em afinidade com as Rules of Engagement da ONU - algumas conceituações que introduzem elementos distintivos num código de conduta militar a ser aplicado em território nacional como as 
de "intenção hostil", "ato hostil" e "oponente". De acordo com o texto, "ato hostil" e “intenção hostil” são, assim, definidos:

a) Intenção hostil - É o propósito de praticar ato delituoso, evidenciado por atitudes e comportamentos suspeitos, indicando a possível ocorrência de hostilidade, com ameaça à integridade física de pessoas ou danos ao patrimônio.

b) Ato hostil - É a ação agressiva e deliberada com o intuito de provocar os efeitos lesivos ou danosos contra, respectivamente, pessoas ou patrimônios (Lima, 2012, p. 34).

O oponente seria "todo indivíduo, atuando integrado a uma força adversa ou isoladamente, que demonstre intenção ou promova ato hostil" (Lima, 2012, p. 35, grifos do autor). Além destas definições, todas as que envolvam legítima defesa autorizam uso da força pelos soldados não apenas contra quem comete um "ato hostil", mas também contra um indivíduo que é avaliado pelo militar como passível ou na iminência de cometer um ato assim. Em suma, a definição de intenção hostil é vaga, ficando a cargo da interpretação e do julgamento do soldado que esteja lidando com a situação. Com isso, abre-se uma margem de interpretação que, em último caso, pode considerar qualquer morador da favela ocupada como oponente ou inimigo. E, como já foi discutido anteriormente neste artigo, ao considerar que qualquer um pode ser “inimigo", os cidadãos destas comunidades são reduzidos à "vida nua", o que culmina com a suspensão de seus direitos que torna suas vidas descartáveis. Esse "inimigo", no contexto das favelas ocupadas, é principalmente o traficante de drogas ou aquele que 
esteja supostamente vinculado ao que se convencionou chamar de "crime organizado" (Souza, 2015; Rodrigues e Serra, 2014).

A ocupação dos complexos de Penha e do Alemão terminou em julho de 2012, quando a Força de Pacificação do Exército passou de espaço para a presença da PM com bases da UPP. A atuação do Exército, no entanto, voltou a ser solicitada no início de 2014 para a ocupação de um outro complexo de favelas, o da Maré, que fica bem à entrada da cidade do Rio de Janeiro, ao lado do aeroporto internacional. Em maio de 2014, cerca de um mês antes do início da Copa do Mundo da FIFA, uma outra Força de Pacificação, modelada no exemplo da anterior, ocupou as favelas do Complexo da Maré ficando presente até maio de 2015. Quer seja com a presença do Exército, quer seja com a da Polícia Militar e as UPPs, as favelas continuam identificadas como regiões hostis e, ao menos parte de seus habitantes, como indivíduos ameaçadores da ordem pública.

Para autores como Pacheco de Oliveira (2014), a ideia da pacificação é uma recuperação feita de uma categoria que nunca havia sido usada para o planejamento urbano. O conceito remonta ao Brasil colonial e era utilizado com as populações autóctones. A ideia de um grupo pacificado era a de um grupo que havia deixado de lado seus antigos costumes por imposição do colonizador. O adjetivo era usado em "comunidades que haviam sido vencidas militarmente e que aceitavam temporariamente o domínio português" (Oliveira, pp. 131, 2014). O adjetivo tinha, portanto, uma carga negativa de imposição civilizatória.

Para Oliveira, a utilização do termo comunidade pacificada não diz respeito somente ao aspecto militar com intenção de acabar com o crime organizado da ocupação. Mais do que isso, sua utilização contemporânea é uma recuperação, uma atualização "da retórica da missão civilizatória" que implica em uma "modificação completa" das comunidades que sofreram tal tipo de intervenção do poder estatal 
(Oliveira, pp.138, 2014). O "outro" da favela seria tão diferente dos costumes do resto da cidade, sendo tão imprevisíveis e perigosos, que uma intervenção com fundo civilizatório e violento tornar-se-ia justificada.

Por conta deste aspecto, de uma alteridade que é passível - e mesmo "necessita" - de intervenção civilizadora, pode-se perceber as nuances da mentalidade que identifica o morador da favela - e não somente o narcotraficante - como o inimigo da paz e da segurança pública que deve ser combatido. A ideia da favela como violenta em si mesma a partir da desqualificação do local, tanto das habitações chamadas comumente de "barracos" - ou na linguagem técnica das estatísticas classificadas como moradias "subnormais" - quanto de seus moradores, pela carga negativa do termo "favelado", revelam a desconsideração do histórico político e cultural destas localidades, tornando-o um ambiente homogêneo na sua estigmatização.

Nesse contexto, no que diz respeito à identificação do inimigo, pode-se citar dois casos de assassinatos ocorridos em favelas do Rio de Janeiro em 2015. O primeiro foi em janeiro quando um menino de 11 anos foi morto na Zona Norte do Rio em uma "comunidade pacificada". A alegação era a de que o menino estava envolvido em um tiroteio entre os policiais e um grupo de traficantes. Segundo os policiais, o jovem portava uma arma e um rádio transmissor ${ }^{6}$. A família negou que a criança tinha qualquer envolvimento com o tráfico e ninguém foi preso. O segundo ocorreu em abril, quando um menino de 10 anos foi morto com um tiro de fuzil na porta de casa no Complexo do Alemão ${ }^{7}$. De acordo com o que foi divulgado pela mídia, o tiro partiu de um policial da UPP e a bala que o atingiu não foi encontrada. O caso também permanece

6 Notícia disponível em <http://g1.globo.com/rio-de-janeiro/noticia/2015/01/familia-de-menino-morto-em-areade-upp-nega-que-ele-estivesse-armado.html $>$ Acesso em 4ago 2015.

7 Notícia está disponível em <http://g1.globo.com/rio-de-janeiro/noticia/2015/04/mae-de-morto-no-alemao-acusanunca-vou-esquecer-o-rosto-do-pm.html>Acesso em4ago 2015. 
sem nenhuma prisão. Ambas as mortes foram justificadas como danos colaterais do combate ao tráfico que ocorrem de forma corriqueira na cidade e que representam um regime de exceção inaugurado nestes espaços, sob a lógica perene do inimigo interno.

Mesmo fora das favelas, moradores que preenchem as categorias preconceituosas de raça e classe social geralmente associadas com habitantes dos morros cariocas e, por isso, com potenciais criminosos, são passíveis de violência policial. Em novembro de 2015, cinco jovens foram assassinados com dezenas de tiros por policiais militares na Zona Norte do Rio de Janeiro ${ }^{8}$. Os policiais serão julgados tanto por homicídio doloso quanto por fraude processual, já que as testemunhas afirmam que os PMs tentaram forjar um "auto de resistência" constituição do campo, portanto, transcende o espaço físico da favela e está mais atrelado ao estereótipo dos habitantes destas localidades que os acompanha para além dos limites das favelas. Ainda com relação à arbitrariedade da decisão sobre a questão do tráfico de drogas e sobre a criminalização dos moradores da favela, é importante destacar que na Lei de Drogas de 2006 consta que o delegado, no momento em que se lavra a infração, avalia se a droga apreendida é para consumo próprio ou para tráfico considerando a quantidade, o local, as condições da ação, as circunstâncias sociais e pessoais e a conduta antecedente do agente envolvido (Brasil, 2006). Esta diferenciação entre o consumidor de drogas (que não pode ser preso no Brasil) e o traficante (que sofre duras penas) é de extrema importância, pois geralmente está relacionada a preconceitos sociais e raciais, tanto por parte dos policiais que fazem a

8 Notícia disponível em $<$ http://extra.globo.com/casos-de-policia/cinco-jovens-sao-fuzilados-dentro-decarro-na-zona-norte-do-rio-18174696.html> Acesso em 04 fev 2016.

9 Foi aprovada no início de 2016 o fím da utilização do termo "auto de resistência" nos boletins de ocorrência. A medida tem como finalidade conferir maior transparência e eficiência na investigação de casos como os dos cinco jovens assassinados no Rio de Janeiro. Ainda que a medida seja um grande avanço na questão dos direitos humanos no país, não é possível saber de que forma afetará a atuação dos policiais militares, principalmente dentro das favelas. Disponível em <http://www1.folha.uol.com.br/cotidiano/2016/01/1725933-resolucao-poe-fim-aotermo-autos-de-resistencia-em-boletim-de-ocorrencia.shtml> Acesso em 04 fev 2016. 
apreensão, quanto por parte dos delegados e juízes que julgam os caso.

Como exposto na reportagem de Marcelo Pellegrini publicada no site da revista Carta Capital, em julho do de 2015'10, pode-se observar um aumento da população carcerária especialmente por conta da prisão de pessoas envolvidas com o tráfico. Já que não há, em lei, quantidades exatas de drogas ilegais que diferenciem os volumes para consumo pessoal e para tráfico, nota-se que as prisões estão mais relacionadas realmente às questões sociais e raciais que às quantidades de drogas em si (Boiteux, 2015). Nesse momento, um julgamento em curso no Supremo Tribunal Federal pode alterar essa situação legal, estabelecendo que se o consumo não pode ser criminalizado, o porte para consumo pessoal também não constituiria crime passível de prisão. De todo modo, fica patente a diferença de tratamento exemplificada no caso dos jovens brancos de classe média da Tijuca e dos jovens negros, alvos preferenciais do encarceramento em massa decorrente da aplicação da Lei de Drogas de 2006.

Tendo em vista essa discussão, o espaço de atuação das UPPs, ainda que parametrado pelas leis vigentes e pelos controles supostamente ativos nos dispositivos do estado de direito acaba se constituindo, na prática, como um espaço de exceção. Nesse espaço, o ator soberano, temporariamente representado pelas forças policiais e militares, detém o poder de decisão sobre a vida que pode ser exterminada, sobre seu futuro e seu tratamento, prescindindo, na prática, da aplicação do ordenamento jurídico padrão. As favelas onde atuam as UPPs constituem, dessa maneira, o "campo", o nomos do espaço político moderno, nos termos agambenianos. Neste espaço, os cidadãos acabam reduzidos à condição do homo sacer, cuja vida torna-se exterminável por um ato que em tese está sujeito à prestação de contas pela perpetração de um crime. Cabe ressaltar, uma vez mais, que a ordem legal no estado de exceção se encontra baseada na

10 Notícia disponível em <http://www.cartacapital.com.br/sociedade/sob-a-lei-espanhola-69-dos-presos-por-traficono-brasil-estariam-livres-3087.html $>$ Acesso em 11 ago 2015. 
decisão do soberano e não nas normas vigentes, ainda que o soberano seja ator também pertencente a elas. A seletividade na aplicação da lei penal e a seletividade no momento em que se pratica o poder máximo sobre a vida e morte, nesses espaços delimitados, obedece a uma lógica extrema do exercício do poder vinculada a um regime alicerçado no poder decisório das instâncias superiores, das quais derivam decisões em prol da manutenção e preservação do Estado, de seu status quo e do regime da propriedade privada e estatal, tendo como alegado fim último a segurança pública. Neste cenário, torna-se possível a perpetuação da figura do "inimigo" e a utilização de instrumentos de emergência para decidir sobre os destinos de sua vida, que termina inserida nas práticas políticas de segurança por um processo de crescente indistinção entre bíos e zoé, entre vida política e vida biológica.

\section{Considerações Finais}

Ao traçar um paralelo entre a lógica governamental da segurança, o uso normal de medidas de exceção e a crise das democracias liberais, Giorgio Agamben (2001) propôs uma análise cuja interseção está situada entre o problema do governo ou da biopolítica, levantado por Foucault, e o problema schmittiano da exceção. Ao enfatizar a inscrição da vida natural ou biológica na ordem jurídico-política do Estado moderno, Agamben chamou a atenção para o fundamento da soberania: o Estado fez do nascimento (da "vida nua") o alicerce encoberto de sua própria soberania, exercendo o controle sobre os corpos em abstrata nudez (Agamben, 2009). Nesse sentido, o estado de exceção se apresenta como o dispositivo através do qual a "vida nua" é, ao mesmo tempo, excluída (exterminável como a figura do homo sacer) e capturada pelo ordenamento, constituindo o fundamento oculto sobre o qual repousa todo o sistema político moderno (Agamben, 
2014). O ponto de interseção entre as análises de Agamben e as reflexões de Michel Foucault e de Carl Schmitt é, precisamente, estes processos análogos de progressiva coincidência entre espaço político e espaço da "vida nua" e a transformação do estado de exceção em técnica de governo dos homens.

Tendo representado o campo como "o espaço que se abre quando o estado de exceção começa a tornar-se a regra" (2014, p.164), Agamben empenhou-se em analisar e explicitar o movimento de perpetuação deste espaço na prática política moderna, e com este, a reprodução da figura do homo sacer. O fortalecimento das políticas estatais de controle, confinamento e punição sobre determinados grupos possibilita o emprego normal dos dispositivos de segurança e exceção no interior do espaço urbano, que assume, em determinadas localidades, a forma do campo, onde o que está em jogo não é mais viver, mas sobreviver (Agamben, 2009). O campo pode ser compreendido, assim, como o espaço vazio, preenchido apenas com o resto, isto é, com aquilo que sobrou entre os corpos concentrados e que constitui apenas "modulações de sobrevivência" (Passetti, 2011, p.51). Nesse sentido, nas sociedades modernas de segurança e controle, os chamados sobreviventes, que se configuram como os restos, podem ser aqueles banidos tanto de seus territórios, como o caso dos refugiados, quanto em seus territórios, como os habitantes das favelas. Como sobrevivente, o "resto insuportável" (idem), torna-se alvo dos higienismos e, ao mesmo tempo, corpo disponível à possibilidade constante do extermínio: a face do "lumpen ocupado" (idem).

Sob um perfil de normalidade, as democracias liberais colocam-se cada vez mais sob o signo da segurança, fazendo referência constante ao estado de exceção e buscando pacificar e controlar a "vida nua", transformando-a em vida política (Agamben, 2001). Nesse sentido, a figura do sobrevivente ou do homo sacer traz consigo um paradoxo de isolamento: ao mesmo tempo em que esta figura é construída sob a forma da sua 
exclusão (no sentido de sua absoluta matabilidade), ela é manejada através de ferramentas de inclusão que buscam capturá-la através da excepcionalidade, controlando-a e pacificando-a. É precisamente através deste paradoxo fundamental que se torna possível compreender a figura do sobrevivente através da óptica de sua transformação tanto em corpo alvo de políticas higienistas, como em corpo exposto à possibilidade constante e incondicionada do extermínio. Este corpo torna-se, então, o novo sujeito da política e, como tal, encontra-se subordinado ao poder soberano e ao seu arbítrio: cabe lembrar que uma das metáforas centrais da comunidade política, representada por Hobbes na figura do Leviatã, é precisamente a composição do corpo político através da junção dos corpos individuais, mantendo sempre “um estreito liame com a vida nua" (Agamben, 2014, p.121). O corpo biopolítico torna-se, então, "a aposta de uma decisão política soberana, que opera na absoluta indiferenciação de fato e direito" (idem, p.167).

Assim, a questão da (in)segurança pode ser entendida a partir da lógica de grupos que são identificados como responsáveis por uma severa ameaça à ordem interna. Essas personagens “indesejáveis" da sociedade são gerenciadas por táticas governamentais que visam a regular ritmos da circulação das pessoas (para dentro e fora das favelas) e suas produtividades, tanto nas atividades legais quanto nas ilegais (que são confinadas ou, pelo menos, contidas nos espaços da favela e nas conexões com autoridades públicas, agentes do aparato de segurança, consumidores e demais grupos ilegais, dentro, fora e nos limiares das favelas). As políticas de segurança pública, como as UPPs e as associações com o governo federal (representadas pelas Forças de Pacificação) conformam parte dessas táticas governamentais. Táticas que ativam relações extremas de "amigo/inimigo" que, por sua vez, ativam táticas de exceção.

Para Schmitt, o estado de exceção é um acontecimento singular caracterizado pela 
suspensão do ordenamento político padrão, o que faz com que o soberano assuma a função da decisão. Para críticos do autor, como Agamben, atualmente a exceção tornouse a regra, representada no arbítrio do Estado de decidir sobre a vida do cidadão. Além disso, ao tornar-se paradigma de governo, percebe-se a construção do "campo", entendido pelo autor como um espaço de exceção permanente, constituído como o lugar da "vida nua", da vida exterminável do homo sacer. É, então, neste espaço que a vida biológica (zoé, a vida comum a todos os seres vivos) é incluída no centro da esfera política (originalmente lugar da bíos), tornando possível a decisão do Estado soberano sobre os destinos desta vida, abarcando ainda a possibilidade de seu extermínio.

A partir destas considerações, pode-se discutir as atuais políticas de pacificação no Rio de Janeiro, nas suas modalidades das UPPs e da Força de Pacificação. Ao reforçar o discurso de que as favelas são os locais da origem dos problemas de segurança e violência na cidade, abre-se espaço para que políticas públicas sejam propostas para estas áreas baseadas na lógica schmittiana do amigo/inimigo. Com isso, as favelas se tornam verdadeiros espaços de exceção, no sentido de que elas representam um espaço da ameaça, no qual o "inimigo" - caracterizado na figura do "criminoso", especialmente, do "traficante" - vive e/ou atua, devendo ser combatido, isolado e, no limite, eliminado. As favelas passam, então, a ser percebidas como a "outra metade da cidade" (Valladares apud Almendra, 2014) dentro das quais é possível tomar medidas especiais que, a qualquer preço, sirvam para conter a violência urbana.

Por conta da dificuldade inerente à questão do narcotráfico de determinar quais são os grupos que devem ser combatidos e com o entendimento das favelas como um espaço de exceção, como um "campo", todo e qualquer habitante do local está sujeito ao arbítrio do poder soberano. No caso das favelas cariocas, o poder soberano está representado temporariamente pela força policial - e, eventualmente, militar - dita 
pacificadora, que tem a prerrogativa de agir de acordo com o que entender ser conveniente para a contenção do "inimigo". Como neste caso qualquer habitante pode ser considerado um inimigo e sua vida, portanto, exterminável, o morador da favela é despido de sua condição de cidadão e reduzido à "vida nua".

Com isso, além de as favelas serem consideradas locais de crime e violência, seus habitantes passam a ser também criminalizados e considerados incivilizados. As UPPs aparecem, então, como forma de garantir a pacificação destes locais para que este "processo civilizatório" possa ocorrer. Como apontam autores como Almendra (2014) e Granja (2015), nas localidades onde há UPPs, uma parte considerável da população entende que quem comanda a favela é a UPP. É essa polícia-soberana agindo para atender a demanda da cidade por segurança pública combatendo o narcotráfico que transforma a vida do morador da favela em exterminável.

Para o morador da favela, passível de ser identificado como "inimigo" (como o narcotraficante), a polícia ou o Exército enquanto Força de Pacificação podem ser ativadores de práticas de exceção. No entanto, há que reparar que essas políticas de segurança e a produção de espaços de exceção são apenas possíveis por conta de uma ampla chancela social, não apenas de moradores da cidade formal, como também de parcelas das populações nas chamadas comunidades que desejam ver o fim das práticas de governos conduzidas por grupos ilegais. O controle, vigilância, prisão e eliminação de pessoas em nome da segurança individual e coletiva não são, desse modo, um mero estratagema policial ou insidioso plano de militarização. Antes de mais nada, eles são movimentos amplamente lastreados por setores da sociedade brasileira. Os aplausos aos blindados que invadiram os Complexos da Penha e do Alemão, em 2010, ou o sucesso dos filmes produzidos sobre o BOPE são apenas pistas que sugerem a existência de uma audiência disseminada que demanda e ampara a repressão e as políticas de pacificação. 
Nesse ponto, vale manter aqui um cuidado analítico, recordando Foucault, para quem o poder não se exerce desde um centro ou a partir do Estado, sendo mera força repressiva que, de forma descendente, oprime e domina. Ao contrário, as modalidades descendentes de exercício de poder, vinculadas à manutenção de determinados regimes políticos e econômicos, não existem somente como mera obra de um grupo dominante. Elas, ao contrário, respondem a uma sofisticada articulação entre interesses de elite e demandas sociais difusas que praticam, elas também, modalidades de controle e governo nos mais ínfimos rincões da sociabilidade humana. Em outras palavras, não há simples imposição de uma ordem política de cima a baixo, mas diferenciadas associações táticas entre interesses de grupos sociais distintos que vão modelando as práticas macroscópicas de poder catalisadas pelo Estado. Assim, em cada favela pacificada ou jovem preso ou morto há que se perguntar quem deseja, apoia ou aplaude - ainda que silenciosamente - a "exceção", convertida mais do que em "regra", em corriqueira e normalizada prática das banalizadas violências cotidianas.

\section{Referências Bibliográficas}

Agamben, Giorgio. Mais além dos direitos do homem. Disponível em www.oestrangeiro.net/política Acessado em 12 de agosto de 2015.

. Means without End Notes on Politics. In: Buckley, Sandra et al. (Org.). Theory of Bounds. Londres: University of Minnesota Press, 2000. Disponível em: <http://roundtable.kein.org/node/620>. Acesso em: 11 jun. 2015.

- 'Security and Terror' 5(4) Theory\&Event, 2001. Disponível em: http://muse.jhu.edu Acesso em: 12 jun. 2015.

. Estado de Exceção. São Paulo: Boitempo Editorial, 2004.

3RASILIANA- Journal for Brazilian Studies. Vol. 4, n.2 (2016). ISSN 2245-4373. 
. Homo Sacer: o poder soberano e a vida nua. Belo Horizonte: Editora UFMG, 2014a.

$\begin{array}{cccc} & \text { Como a obsessão por segurança muda a democracia. Le Monde Diplomatique } \\ \text { Brasil, } & \text { janeiro } & 2014 \mathrm{~b} . & \text { Disponível }\end{array}$ http://www.diplomatique.org.br/artigo.php?id=1568 Acesso em: 06 jun. 2015

Almendra, Dinaldo. As UPPs, as elites e a imprensa: militarização e consumo no processo de "pacificação" de favelas no Rio de Janeiro. Revista Paranaense de Desenvolvimento, Curitiba, vol. 35, n. 126, pp. 61-89, jan/jun, 2014.

Amar, Paul. Operation Princess in Rio de Janeiro: policing 'sex trafficking', strengthening worker citizenship, and the urban geopolitics of security in Brazil", Security Dialogue, vol. 40, n. 4/5, pp. 513-541, 2009.

Arendt, Hannah. A Condição Humana. 09 ed. Rio de Janeiro: Forense Universitária, 1999.

.As origens do totalitarismo. Tradução de Roberto Raposo. São Paulo: Companhia das Letras, 2012.

Arias, Enrique Desmond. Drugs and democracy in Rio de Janeiro: trafficking, networks, and Public Security. Raleigh: University of North Carolina Press, 2008.

Beck, Ulrich. Sociedade de Risco: rumo a uma outra modernidade. Tradução de Sebastião Nascimento. São Paulo: Ed. 34, 2011.

Boiteux, Luciana. Contradicciones y ambigüedades en la política brasileña de drogas en el siglo XXI: avances y retrocesos in Labate, B.C.; Rodrigues, T. (eds.). Drogas, política y sociedad en América Latina y el Caribe. México D.F.: CIDE, 2015, p. 317-340.

BRASIL. Presidência da República. Decreto no 54.216, de 27 de agosto de 1964. Lei de Entorpecentes. Brasília, D.F. 1964.

Presidência da República. Lei Complementar no 97, de 9 de junho de 1999. Normas gerais para a organização, o preparo e o emprego das Forças Armadas. Brasília, D.F. 1999

Cabeleira, Mayara de Martini. UPP e UPP Social: novas politicas, outras polícias. In: Ecopolíticas. nº5. pp.169-174. 2013. 
Cano, Ignácio (coord.). "Os Donos do Morro": uma avaliação exploratória do impacto das unidades de polícia pacificadora (UPPs) no Rio de Janeiro. Rio de Janeiro: Fórum Brasileiro de Segurança Pública e Laboratório de Análise de Violência da (LAV-UERJ), mai. 2012.

Granja, Patrick. UPP: o novo dono da favela (Cadê o Amarildo?). Rio de Janeiro: Revan/ICC, 2015.

Krauthasen, Ciro; Sarmiento, Luis. Cocaína \& Co.: un mercado ilegal por dentro. Bogotá: Tercer Mundo Editores, 1991.

Leite, Márcia Pereira. Da "metáfora da guerra" ao projeto de "pacificação": favelas e políticas de segurança pública no Rio de Janeiro. In: Revista Brasileira de Segurança Pública. São Paulo. v.6, nำ2. pp.374-389. 2012.

. Entre a "guerra" e a "paz": Unidades de Polícia Pacificadora e gestão de territórios de favela no Rio de Janeiro. In DILEMAS: Revista de Estudos de Conflitos e Controle Social. Vol.7, nº 4. pp.625-642. 2014.

Lima, Carlos Alberto de. Força de Pacificação: os 583 dias da pacificação dos complexos da Penha e do Alemão. Rio de Janeiro: Agência 2A Comunicação, 2012.

Oliveira, João Pacheco de. Pacificação e tutela militar na gestão de populações e territórios. In: Mana 20(1), 2014, pp.125-161.

Passetti, Edson. Governamentalidade e violências. Currículo sem Fronteiras. Vol. 11., n. 1, pp. 42-53, 2011.

Rodrigues, Thiago. Guerra e política nas relações internacionais. São Paulo: Educ, 2010.

Narcotráfico e militarização nas Américas: vício de guerra. Contexto Internacional, vol. 34, noำ, Rio de Janeiro, jan./jun. 2012.

Narcotráfico, uma guerra na guerra (2ª edição). São Paulo: Desatino, 2012a.

Rodrigues, Thiago; Serra, Carlos Henrique Aguiar. Estado de direito e punição: a lógica da guerra no Rio de Janeiro. Curitiba: Revista Paranaense de Desenvolvimento. Vol.35, nำ126. 
pp.91-108. 2014.

Santos Filho, Julio Cesar de Mendonça. A militarização da segurança pública e a vida nua: o caso das UPPs. 2013. Disponível em <http://www.inest.uff.br/index.php/selecione-umevento/biblioteca-112/pesquisa-avancada/3-estudos-estrategicos/23-a-militarizacao-daseguranca-publica-e-a-vida-nua-o-caso-das-upps>. Acesso em 20 jul 2015.

Schmitt, Carl. Political Theology. Cambridge: MIT Press, 1985 . The Concept of the Political. Chicago: The University of Chicago Press, 1996.

Valladares, Licia. A invenção da favela: do mito de origem ao favela.com. Rio de Janeiro: FGV Editora, 2005 